follows: "As to the assertion that the lower ribs are drawn downwards and backwards by the simultaneous contraction of the diaphragm, intercostals, and serratus posticus inferior, it is sufficient to remark that clinicians who have opportunities of watching the isolated actions of muscles in disease are all agreed that the diaphragm elevates the lower ribs." The disingenuou ness of the attempted argumentation of this sentence can hardly be surpassed, even in the records of legal, or theological, sophistication. Whose, I wonder, is "the assertion that the lower ribs are drawn downwards and backwards by the simultaneous contraction of the diaphragm, intercostals, and serratus posticus inferior"? Most assuredly it is not mine, as every reader of my letter can see. I have made the incontrovertible statement that such is the action of the serratus posticus inferior, acting singly. By so acting on the ribs it corrects the influence of the contracting diaphragm which, if left unopposed, would have the effect of narrowing " the basal section of the thorax, where most expansion is attainable." (I quote my own words.) It is, of course, superfluous to point out to those who have perused, and understood, my description of the action of the diaphragm that the testimony derived from "clinicians who have opportunities of watching the isolated actions of muscles in disease" was instruction wasted-so far as the present writer is concerned, as well as being conspicuously imperfect.

The contents of Dr. Keith's original paper call for comment under many other heads; but I will select only a few. On the first page, as the author discusses "the causes of the variab lity" of the level of the diaphragm after death, we are told that "the elasticity of the lungs draws the diaphragm up as far as it will gield. The high or low position of the diaphragm depends very little on the distension of the abdomen or of the bowel." Regarding these statements I must say that in the present state of physical and anatomical knowledge they read rather "funny." It is unnecessary, of course, to point out that the lungs, or their elasticity, have no direct connexion with the diaphragm. And every tyro in physiology knows, or surely should know, that the expansion of the lungs during inspiration is due to the atmospheric pressure-the regulation $15 \mathrm{lb} .(14.7)$ to the square inch-on the mucous surfaces, when the active contraction of the muscles of inspiration has expanded the chest. by bearing a certain proportion of the same pressure from off the cutancous (external) surface. The external weight lifted (or pushed) off the surface of the body is represented by that used by the internal limb of the gaseous balance in distension of the tubes and vesicles, as the pulmonary pleura follows the movements of the walls of the expanding chest. And when the inspiratory muscles have ceased to ac the chest walls follow the contracting elastic tissue of the lung, till equilibrium of balance between the external and internal pressures is again reached. This atmospheric pressure acts with obvious directness on the circumferential chest-wall in squeezing it-in corset fashion-back to its original position; but it appears to be sometimes forgotten that the atmospheric pressure is also the sole efficient agent in pushing up the diaphragm during ordinary expiration, and more especially still in that which constitutes the last obvious movement of life.

On page 2 the reader is told that he "must look upon the diaphragm as a fan-shaped digastric muscle." This appears to be Dr. Keith's own special discovery. "The central tendon corresponds to the intermediate tendon of such a muscle as the digastric or rectus abdominis." To this physico-metaphysical statement I take leave to take special exception. The preposterous statement that the diaphragm is a digastric muscle cannot for a moment be entertained by any skilled physiological anatomist. It would be less intolerable, indeed, to speak of it as a myrio-gastric muscle, but even such description would be very unsatisfactory. It is rather difficult to comprehend how anyone acquainted with the diaphragm can hold the view that the action of each individual portion is to draw its circumferential attachment towards the spine. Ererybody who knows its structure knows that the lateral fibres, on either side, pass from the ribs towards the central tendon and that the only possible effect of their contraction-in addition to reducing the upward convexity-is to draw these yielding bones towards that tendon; that is to say, upwards and inwards. The fibres attached to the central leaflet, of course, have necessarily the collective action of drawing the xiphoid cartilage and adjacent cartilages of the lower ribs towards the spine. But this movement may almost be regarded as incidental. The modern geometer "squares the circle" by treating every infinitely small segment of the circumference as a straight line. By this-"quam proxime" correct-assumption he resolves the space into a eries of infinitely narrow parallel rectangles. The calculation is then easy. But his rectangles must be parallel. The diaphragm undoubtedly may, for fanciful purposes, be looked upon as a structure composed of an infinite number of infinitely small rectangular digastric muscles. The rectangular bundles are, however, not paraliel, and cannot possibly be made so; and, accordingly, the mathematical methods of "summation of series" cannot be made to apply.

I more especially wonder how it is that in this unusually original thesis Dr. Keith has ignored the incontrovertible fact that if the diaphragm acted according to his view-by drawing all its distal attachments towards the spine-it would very seriously limit the space behind the (almost vertical) posterior fibres of the muscle, which is precisely the region where, under existing arrangements, the lungs undergo the greatest proportion of expansion. A glance at Fig. 1 of his own paper will show this. I must also point out the fact that the greater firmness of the chest-wall in this region renders the wearing of corsets more tolerable than could otherwise be the case.

In the discussion of the "action on the ribs" we are told in regard to that on the abdominal ends of the six lower ribs: "this of the three directions in which it expands (? expends) the force of each contraction is the most difficult to understand." And the writer proceeds to ask, "How is it that the ends of those diaphragmatic ribs do not move in towards the origin of the diaphragm from the lumbar region of the spine?" In this connexion I beg leave to state that both difficulties are wholly of Dr. Keith's own creation. If the diaphragm were, as he states, a digastric muscle, the phenomenon would be simply impossible to understand, even after the most careful perusal of his preposterous explanation. But as the diaphragm is not a digastric muscle, endowed with only anteroposterior activity, the difficulty only exists in his own imagination.

There are other points in this very original paper of Dr. Keith's which may very easily be made to yield to criticism, but it is probably better to add nothing further to an already too lengthy communication.

I am, Sils, yours faithfully, John KNotT, M.D. Dub.

\section{THE RAPID TREATMENT OF CONGENITAL HIP-MISPLACEMENT.}

\section{To the Editors of THE LANCET}

8IRs, -The profession having now had time to cool down from the excitement caused by the demonstrations of Professor Lorenz-a little study and calm reflection will show it that miracles must not be expected. Already a long list of failures and very serious accidents have been recorded, and as the public, which is ignorant of such matters, will be clamouring for marvellous cures it is necessary that practitioners should be on their guard when advising, and though an effort has been made by medical and other papers to caution the public that complete cures are not to be expected and that the plan is not free from considerable risk it is unlikely that this will reach the very extensive circle to which the operation is known. Hence much may rest with the advice medical men give, though the public is prone to take matter into its own hands when such promising results are expected. Should Professor Lorenz ultimately succeed in demonstrating anything approaching a complete cure he will be a great benefactor to humanity and I shall try to be the first to congratulate him. In the meantime it seems to me that the odds are heavy against forcible reposition as they were against the open cutting methods and for the following reasons. The child walks late, usually about the end of the second year, and though she falls about the parents think she will grow out of the trouble, so that these cases are often not brought for treatment until the child has walked some time. Hence the head and neck of the femur are more or less deformed, the acetabulum remains very incomplete, the ligaments are overstretched, and some of the muscles are shortened and others lengthened. How is it possible to correct all this by any method? It is quite right to try to do our best to remedy the deformity but to run considerable risk in so doing, unless 
we can guarantee something better than by older plans, seems to me to be scarcely justifiable. Of course, if one could promise something more permanent than has hitherto been done and more nearly reaching a perfectly anatomical and functional condition then one may run the risks after explaining their possibility to the parents. As this cannot be done it is better to adhere to more gradual plans in the interests of the patients and the surgeon.

As most of the soft parts which normally help to keep the bone in place are torn through before reduction, socalled, is accomplished and as the limbs are put up at about a right angle and kept so for many months, where can the pressure of the femoral head to mould and to enlarge the acetabulum come from? And as the gaps in the torn parts are filled and they become elongated it seems to me that a loose joint, very liable to displacement in almost any direction, is made and consequently secondary displace ments-supposing a true reduction has been made-are common. Seeing that the head of the femur is larger than the acetabulum and of a different shape how can it possibly keep in place? Even by the open cutting plan when the acetabulum has been enlarged and shaped to the bead it very frequently becomes displaced on walking unless ankylosis has occurred, and as in this operation it was found to be a fault to cut the muscles, surely when they are torn through the weakening effect must be at least as great. Moreover, in the "splits" position a large part of the femoral head is downward outside the acetabulum and the small part remaining in contact, even if it do so, would need constant pressure on the sole of the foot or through the knee to produce absorption. Why Professor Lorenz prefers patients aged four years for his operation I cannot understand, for walking increases the mischief and the earlier treatment is undertaken the more hope is there for improvement.

London, W. I am, Sirs, yours faithfully, H. A. Reeves.

\section{A CASE OF HERNTA INTO THE FOSSA DUODENO-JEJUNALIS.}

To the Editors of $\mathrm{THE}$ LANCET.

SIRs,-In THE LANCET of Jan, 24th, p. 236, is a paper bearing the above title. This paper contains the record of a case of internal hernia, with comments upon the anatomical condition of the parts, but it completely ignores all the work that has recently been published upon tbis subject. The description given is clear and leaves one in no doubt that the condition found was one of left duodenal hernia. The fossa in which this hernia always lies is known as the fossa of Landzest. The fold bounding the orifire of the fossa in front is known as the plica venosa from the fact that it is raised up by the inferior mesenteric vein for which it forms in early life a sort of mesentery. There is neither need nor justification for any new term such as that suggested for the subject is already burdened by a florid and exuberant nomenclature. The hernia does not occur into the fossa duodeno-jejunalis; indeed, it is doubtful whether a hernia has ever occurred into this fossa. The probability is that the hernia is always congenital and the condition of the fossa in which it lies must therefore be studied in the foetus or the young child. When examined thus early: it will be found that a hernia into the fossa of Landzest and the fossa duodeno-jejunalis (the inferior duodenal fossa) are quite distinct. A specimen in the museum of St. Thomas's Hospital shows the hernia in an earlier stage than any other museum specimen in this country. The anatomy and surgery of the duodenal fossæ are fully discussed in the works of Jonnesco and Brösike and in my own work on "Retroperitoneal Hernia." I am, Sirs, yours faithfully,

Jan. 31st, 1903.

B. G. A. Moynihan.

\section{BRISTOL AND THE NON-VENTILATION OF SEWERS. \\ To the Editors of THE LANCET.}

SrRS, - The Bristol argument is really based on a double fallacy. The first fallacy is that the Bristol sewers are nonventilated and the exposure of this fallacy by your Special Sanitary Commissioner could scarcely be more complete. ${ }^{1}$ The second fallacy is that Brighton and Croydon are ventilated towns. This is not true, either in a legal or a sanitary sense. The Bristol position is therefore doubly false and when we consider what the practical outcome of it is, or may be, it is perniciously false.

In regard to the second fallacy your Commissioner touches the real truth when he says: "The example of Bristol seems to indicate that the ventilation of sewers has been so badly managed in some towns that Bristol without any management has obtained [health] results which are quite as good if not better." "Badly managed" is perhaps not the most appropriate term to use in the circumstances, for the trouble does not really lie in "the management" but in the means of ventilation employed in the towns misnamed ventilated.

Brighton and Croydon have been singled out as examples of ventilated towns in this discussion, I presume, because they have adopted, to a large extent at least, the high shaft system. Now, if the grid system is inadequate much more so is the high shaft system. High shafts are altogether a delusion, having not only all the faults of the grid system but in a greater degree and are therefore less efficient as a means of ventilation under all atmospheric conditions. In addition they are most expensive and unsightly and, as in the present case, fraught with public danger in the false conclusions to which they are capable of leading sanitary authorities honestly desiring to do their appointed public duty. The true inference, therefore, to be drawn from the fact that the results at Brighton and Croydon are no better than those at Bristol is that the system at Brighton and Croydon requires improvement and not that the Bristol practice should be set up as a model to be copied by other towns.

Your Commissioner's article is a most invaluable one, not only within its own limits but in the questions to which it gives rise. For example, how is it that with such a splendid public health service we are continually seeing the public health break down under severe epidemic foul air disease? I am folly convinced that the key to the answer lies in the fact that the advantages of proper sewer ventilation to public health are not yet understood by sanitary authorities. Again, how is it that after so much discussion, scientific research, and costiy experimentation the sewage disposal problem is to-day in the unsatisfactory condition it is? Again, I am convinced that the key to the answer is to be found in the fact that the solution of the sewage problem should, as I have submitted in my evidence before the Royal Commission, begin with the perfect ventilation of the sewers. Your Conmissioner, therefore, has rendered a greatly needed service to the public and I trust it will have an immediate and practical outcome, for in a few weeks the bad sewergas period will be on us again

\section{I am, Sirs, yours faithfully,}

Victoria-street, Westminster, S.W., Jan. 20th, 1903.

$$
\text { W. Brown. }
$$

\section{WHY IS NOT SMALL-POX SPEEDILY "STAMPED OUT" LIKE OTHER EPIDEMIC DISEASES? \\ To the Editors of $\mathrm{THE} \mathrm{LANCET}$.}

SIRS,-This question is often asked, yet the answer is very simple. The only true check to the spread of variola among dense communities of people is systematic and efficient vaccination of all infants and the revaccination of children at the school age. Unfortunately this disease alone of all others has been made the sport of political schemers and place-hunters who are content to sell their birthrightvaccination-for "a mess" of unseemly pottage. Yielding to the ignorant outcry against the protective influences of sterilised lymph our Government has introduced the bogey of "the conscientious objector." As a practical illustration of the advantages of intrusting compulsory powers for vaccination to a central government authority directly concerned with the maintenance of public health and the prevention of epidemic disease $I$ herewith send some details from a letter just received from a clergyman who has permanent charge of a mission station in the island of Barbados. Fortunately the authorities in this and many of our distant colonies are not fettered in their action by the wire pullers of political parties, so that whatever is really beneficent for the community can be carried out under the advice of the executive medical officers.

The Gorernment of the island, viewing with alarm the 